\title{
IDENTIFIKASI JAMUR DERMATOPHYTA PENYEBAB TINEA UNGUIUM PADA KUKU KAKI PETANI KELAPA SAWIT BERDASARKAN PENGGUNAAN ALAS KAKI DI DESA PAUH MENANG KECAMATAN PAMENANG KABUPATEN MERANGIN, JAMBI
}

\author{
Imas Latifah ${ }^{1)}$, Natan Sulistiawan ${ }^{1)}$ \\ ${ }^{1}$ Program Studi Analis Kesehatan, Fakultas Kesehatan, Universitas Mohammad Husni Thamrin \\ Correspondence author: Imas Latifah, imaslatifah17@yahoo.com, Jakarta, Indonesia
}

\begin{abstract}
ABSTRAK
Tinea unguium merupakan infeksi pada lempeng kuku yang disebabkan oleh jamur Dermatophyta. Jamur golongan Dermatophyta mempunyai sifat keratonik, sehingga dapat menyebabkan kuku rapuh dan merusak struktur kuku. Tinea unguium biasanya terjadi karena kebersihan kuku yang kurang baik dan dapat pula dari lingkungan sekitar, seperti kontak langsung dengan tanah atau lumpur. Penelitian ini bertujuan untuk mengetahui jamur Dermatophyta penyebab Tinea unguium pada kuku kaki petani di Desa Pauh Menang Kecamatan Pamenang Kabupaten Merangin, Jambi. Metodelogi penelitian ini menggunakan metode deskritif analitik. Besar sampel yang diperiksa sebanyak 30 orang. Bahan pemeriksaan ini berupa kerokan kuku kaki petani kelapa sawit yang diperiksa secara langsung $\mathrm{KOH} 20 \%$ dan pemeriksaan biakan dengan media SDA (+). Berdasarkan pemeriksaan langsung $\mathrm{KOH} 20 \%$ didapatkan elemen jamur yang mengindikasikan jamur Dermatophyta yaitu hifa sejati dan artrospora, sedangkan pemeriksaan biakan berdasarkan faktor penyebab yang diteliti, yaitu penggunaan alas kaki 3 sampel positif $(20 \%)$, diketahui P. value $0,068(\mathrm{p}>0,05)$. Berdasarkan jenis alas kaki yang digunakan 0 sampel positif $(0 \%)$, diketahui $\mathrm{P}$ value $0,189(\mathrm{p}>0,05)$. Dari hasil penelitian ini dapat disimpulkan bahwa ditemukan jamur Dermatophyta pada pemeriksaan langsung dan biakan dengan spesies Trichophyton rubrum dan tidak ada hubungan penggunaan alas kaki dengan infeksi jamur Dermatophyta penyebab Tinea unguium pada petani kelapa sawit.
\end{abstract}

Kata Kunci $\quad$ : Tinea unguium, Petani Kelapa Sawit, Alas Kaki.

\begin{abstract}
Tinea unguium is an infection of the nail plate caused by the fungus Dermatophyta. Dermatophyta fungi have keratonic properties, which can cause brittle nails and damage nail structure. Tinea unguium usually occurs due to poor nail hygiene and can also be from the surrounding environment, such as direct contact with soil or mud. This research aims to find out the fungus Dermatophyta causes Tinea unguium on the toenails of farmers in Pauh Menang Village Pamenang District Merangin Regency, Jambi. This research method of logic uses the deskritive method of analytics. The sample was examined by 30 people. This inspection material is in the form of toenails of palm oil farmers who are directly inspected KOH $20 \%$ and breeding checks with SDA media (+). Based on direct examination of $\mathrm{KOH} 20 \%$ obtained fungal elements indicating dermatophyta mushrooms namely true hyphae and artrospora, while breeding examination based on the causative factors studied, namely the use of footwear 3 positive samples (20\%), known P. value 0.068 ( $p>0.05)$. Based on the type of footwear used 0 positive samples (0\%), known P value 0.189 ( $p>0.05$ ). From the results of this study it can be concluded that dermatophyta fungus is found on direct examination and breeding with trichophyton rubrum species and there is no relationship of footwear use with dermatophyta fungal infections causing Tinea unguium in palm oil farmers.
\end{abstract}

Keywords : Tinea unguium, Palm Oil Farmer, Footwear.

Open Journal System (OJS): journal.thamrin.ac.id 


\section{PENDAHULUAN}

Tinea unguium merupakan infeksi pada lempeng kuku yang disebabkan oleh jamur Dermatophyta. Berdasarkan penelitian menyebutkan $80-90 \%$ kasus Tinea unguium disebabkan oleh jamur Dermatophyta khususnya Trichophyton rubrum dan Trichophyton mentagrophytes. Gejala yang seringkali nampak pada infeksi ini adalah kerusakan pada kuku, diantaranya kuku menjadi lebih tebal dan nampak terangkat dari dasar perlekatannya, pecah-pecah, tidak rata dan tidak mengkilat lagi, serta perubahan warna lempeng kuku menjadi putih, kuning, coklat hingga hitam (Setianingsih, dkk, 2015 : 156).

Infeksi pada kuku dapat menyerang seseorang yang bekerja atau melakukan kontak langsung dengan lingkungan yang lembab dan kotor seperti petani kelapa sawit. Profesi sebagai petani kelapa sawit sangat beresiko terkena jamur terutama pada kuku kaki karena petani bekerja secara langsung di daerah yang basah, lembab dan juga kotor (Graham, dkk. 2005).

Tinea unguium terjadi di seluruh belahan dunia. Dapat terjadi baik pada anak-anak maupun dewasa. Prevalensi Tinea unguium meningkat sesuai dengan pertambahan usia. Sekitar 1\% pada individu $<18$ tahun dan hampir 50\% pada usia $>70$ tahun. The Archilles project memperkirakan prevalensi Tinea unguium di Eropa sekitar 27\%, di Amerika Utara sebesar 13,8\% dan di Indonesia sekitar 5\% peningkatan prevalensi ini dikarenakan peningkatan imunosupresi seseorang, dan kebiasaan tidak menggunakan alas kaki. Tinea unguium lebih banyak terjadi pada laki-laki dan biasanya dikaitkan dengan Tinea pedis (Perez, dkk, ED et al, 2009 ; 26 (1) : p. 228-32.).

Prevalensi Tinea unguium di Asia tenggara diketahui sangat rendah jika dibandingkan dengan dengan negara-negara barat. Faktor-faktor yang mempengaruhi epidemiologi infeksi diantaranya adalah iklim, geografi, dan imingrasi, selain sosio-ekonomi dan budaya, serta faktor predisposisi lainnya yang memudahkan terjadinya Tinea unguium serupa dengan penyakit jamur superfisial lainnya, yaitu kontak langsung dengan tanah maupun hewan, kelembaban, trauma berulang pada kuku, penurunan imunitas. Gaya hidup tertentu misalnya bekerja pada lingkungan basah, menggunakan sepatu tertutup dalam jangkau waktu yang lama, tidak menggunakan alas kaki akan memudahkan terjadinya infeksi Tinea unguium. Perbedaan geografi memberikan perbedaan pada pola epidemiologi dan etiologi Tinea unguium (Bramono, $2001: 47$ ).

Aktivitas petani yang sehari-harinya bertani memiliki kebiasaan tidak menggunakan alas kaki saat melakukan pekerjaannya, sehingga beresiko terinfeksi karena lumpur dengan mudah masuk kedalam kuku kaki dan dapat menyebabkan terinfeksi jamur (Nurmalasari, A. Andani,G.R. 2016).

Desa Pauh Menang Kecamatan Pamenang Kabupaten Merangin, Jambi, merupakan daerah perkebunan kelapa sawit. Perkebunan kelapa sawit di Desa Pauh Menang ini memiliki jenis tanah berpasir, tanah gambut (tanah yang basah dan lembab) dan rawa. Mayoritas mata pencaharian penduduk disana berkerja sebagai petani kelapa sawit, penduduk yang sehari-harinya bertani di kebun 
kelapa sawit memiliki kebiasaan tidak menggunakan alas kaki saat melakukan pekerjaannya, jarangnya mencuci kaki setelah bekerja, dan kebanyakan kuku kaki petani kelapa sawit memiliki kelainan atau kerusakan, seperti warna kuku coklat kekuningan permukaan tidak rata, kuku rapuh atau mengeras.

Hal inilah yang menjadi kekhawatiran bila kebiasaan penduduk khususnya, yang bekerja sebagai petani kelapa sawit yang tidak menggunakan alas kaki saat bekerja sehingga lumpur, tanah dan kotoran dengan mudah masuk kedalam kuku kaki dan menyebabkan perkembangan jamur dan tidak memperhatikan kebersihan kuku terutama kuku kaki. Petani tersebut menganggap kuku, khususnya kuku kaki tidak begitu penting, padahal kuku yang dalam waktu lama tidak dibersihkan akan menimbulkan bau tidak sedap dan membusuk, serta akan merubah bentuk dan warna kuku, sehingga dapat menyebabkan penyakit pada kuku yaitu Tinea unguium (Amaran, 2010 : 47).

Selama ini Desa Pauh Menang belum pernah dilakukan penelitian mengenai Tinea unguium pada kuku kaki. Sementara kenyataan di lapangan memungkinkan seringnya hal ini terjadi, karena di sebabkan oleh berbagai faktor seperti kelembaban, trauma berulang, penurunan imunitas, serta sumber infeksi jamur seperti lingkungan, air dan tanah, serta kurangnya mencuci kaki dengan sabun (kebersihan kuku) waktu pekerjaan juga dapat mempengaruhi tumbuhnya jamur pada kuku kaki, seperti lamanya bekerja sebagai petani dan durasi bekerja di perkebunan kelapa sawit setiap harinya.

Keadaan diatas mendorong penulis untuk melakukan penelitian tentang identifikasi jamur Dermatophyta sebagai penyebab Tinea unguium pada kuku kaki petani kelapa sawit berdasarkan penggunaan alas kaki dan populasi pada penelitian ini adalah seluruh petani kelapa sawit yang ada di Desa Pauh Menang Kecamatan Pamenang Kabupaten Merangin, Jambi, sedangkan sampel yang di ambil adalah petani yang bersedia diambil sebagai sampel.

\section{METODELOGI PENELITIAN}

Pengambilan sampel dilakukan pada tanggal 20 Juli-22Juli 2018 di Desa Pauh Menang Kecamatan Pamenang Kabupaten Merangin, Jambi. Pemeriksaan Laboratorium secara langsung dan biakan dilakukan pada tanggal 25 Juli-07 Agustus 2018 di Laboratorium Biologi, Universitas MH. Thamrin Jakarta. Populasi pada penelitian ini adalah seluruh petani kelapa sawit di Desa Pauh Menang Kecamatan Pamenang Kabupaten Merangin, Jambi yang berjumlah 51 orang. Sampel yang dipakai pada penelitian ini adalah petani kelapa sawit yang bersedia untuk diambil kerokan kukunya yaitu sebanyak 30 orang.

Analisa Univariat nyaitu Data-data yang diperoleh dari penelitian dihitung, presentase bahan pemeriksaan yang positif jamur Dermatophyta terhadap seluruh bahan pemeriksaan. Adapun rumus perhitungannya adalah sebagai berikut : 


$$
x=\frac{\text { Jumlah Sampel }(+)}{\text { Jumlah Sampel yang diperiksa }} \times 100 \%
$$

Analisis Bivariat nyaitu Dilakukan terhadap dua variabel yang diduga berkolerasi atau berhubungan.

Metode analisis data yang digunakan dalam penelitian ini adalah teknik statistik Chi Square.

Keterangan :

P. value $<0,05$ : Hubungan bermakna

P. value $>0,05:$ Hubungan tidak bermakna

\section{Hasil dan Pembahasan}

\section{Hasil}

Persentase Tinea Unguium

Pemeriksaan Langsung

Hasil pemeriksaan mikroskopis secara langsung dengan menggunakan $\mathrm{KOH} 20 \%$ pada 30 sampel kerokan kuku kaki petani kelapa sawit di Desa Pauh Menang Kecamatan Pamenang Kabupaten Merangin, Jambi, berdasarkan elemen jamur yang ditemukan, 77\% ditemukan elemen jamur dan 23\% tidak ditemukan elemen jamur. Hasil dapat dilihat pada tabel 1 :

TABEL 1.

\section{Distribusi Frekuensi Hasil Pemeriksaan Langsung Kerokan Kuku Kaki Petani Kelapa Sawit di Desa Pauh Menang Kecamatan Pamenang Kabupaten Merangin, Jambi.}

\begin{tabular}{lcc}
\hline \multirow{2}{*}{ Elemen Jamur } & \multicolumn{2}{c}{ Hasil } \\
\cline { 2 - 3 } & Jumlah & Persentase \\
\hline Spora & 20 & $67 \%$ \\
Hifa Sejati dan Spora & 2 & $7 \%$ \\
Hifa Sejati dan Artrospora & 1 & $3 \%$ \\
Negatif & 7 & $23 \%$ \\
\hline Total & 30 & $100 \%$ \\
\hline
\end{tabular}

(Sumber : Data Primer, 2018)

Berdasarkan Hasil penelitian pada tabel 1, dari 30 sampel kerokan kuku kaki petani kelapa sawit, didapatkan hasil elemen jamur spora 20 sampel (67\%), hifa sejati dan spora 2 sampel (7\%), hifa sejati dan artrospora 1 sampel (3\%), sedangkan tidak ditemukan elemen jamur terdapat 7 sampel (23\%). Untuk lebih memastikan bahwa hasil dari pemeriksaan langsung $\mathrm{KOH} 20 \%$ maka dilakukan pemeriksaan biakan pada media SDA (+). Untuk pemeriksaan langsung $\mathrm{KOH} 20 \%$ bukanlah standar untuk pengamatan jamur, tetapi hanya sebagai penyaring ada dan tidaknya infeksi jamur. 
Pemeriksaan Biakan

Hasil pemeriksaan biakan dengan SDA (+) pada 30 sampel kerokan kuku kaki petani kelapa sawit di Desa Pauh Menang Kecamatan Pamenang Kabupaten Merangin, Jambi, terdapat 3 sampel (10\%) positif jamur Dermatophyta. Hasil dapat dilihat pada tabel 2 :

TABEL 2.

Distribusi Frekuensi Hasil Pemeriksaan 30 Biakan Jamur pada Kerokan Kuku Kaki Petani Kelapa Sawit di Desa Pauh Menang Kecamatan Pamenang Kabupaten Merangin, Jambi.

\begin{tabular}{lcc}
\hline \multirow{2}{*}{ Jenis Jamur } & \multicolumn{2}{c}{ Hasil } \\
\cline { 2 - 3 } & Jumlah & Persentase \\
\hline Dermatophyta & 3 & $10 \%$ \\
Non Dermatophyta & 27 & $90 \%$ \\
\hline Total & 30 & $100 \%$ \\
\hline
\end{tabular}

(Sumber : Data Primer, 2018)

Berdasarkan Hasil penelitian pada tabel 2, dari 30 sampel kerokan kuku kaki petani kelapa sawit, telah dilakukan pemeriksaan biakan dengan media SDA (+), didapatkan hasil jamur golongan Dermatophyta sebanyak 3 sampel (10\%) dan jamur golongan non Dermatophyta sebanyak 27 sampel $(90 \%)$.

TABEL 3.

Distribusi Frekuensi Jamur Dermatophyta pada Kerokan Kuku Kaki Petani Kelapa Sawit di Desa Pauh Menang Kecamatan Pamenang Kabupaten Merangin, Jambi.

\begin{tabular}{lcc}
\hline \multirow{2}{*}{ Jenis Jamur Dermatophyta } & \multicolumn{2}{c}{ Hasil } \\
\cline { 2 - 3 } & Jumlah & Persentase \\
\hline Trichophyton rubrum & 3 & $10 \%$ \\
Trichophyton mentagrophytes & 0 & $0 \%$ \\
Epidermaphyton flocossum & 0 & $0 \%$ \\
\hline Total & 3 & $10 \%$ \\
\hline
\end{tabular}

(Sumber : Data Primer, 2018)

Berdasarkan hasil penelitian pada tabel 3, didapatkan hasil jamur Dermatophyta penyebab Tinea unguium dengan spesies yaitu Trichophyton rubrum 3 sampel (10\%), Trichophyton mentagrophytes 0 sampel (0\%), dan Epidermaphyton flocossum 0 sampel (0\%).

Hubungan Jamur Dermatophyta sebagai Jamur Penyebab Tinea unguium berdasarkan Faktor yang mempengaruhinya.

Berdasarkan kebiasaan dan perilaku selama bekerja di kebun kelapa sawit yang dapat menyebabkan timbulnya Tinea unguium seperti penggunaan alas kaki selama bekerja, terdapat 3 sampel (20\%) 
jamur Dermatophyta dengan spesies Trichophyton rubrum yang tidak menggunakan alas kaki. Hasil dapat dilihat pada tabel 3 :

TABEL 4.

Hubungan Tinea unguium (Dermatophyta) dengan Faktor yang Mempengaruhi pada Petani Kelapa Sawit di Desa Pauh Menang Kecamatan Pamenang Kabupaten Merangin, Jambi.

\begin{tabular}{|c|c|c|c|c|}
\hline \multirow{2}{*}{ Faktor Yang Mempengaruhi } & \multicolumn{2}{|c|}{ Dermatophyta } & \multirow{2}{*}{ Jumlah } & \multirow{2}{*}{ P. Value } \\
\hline & $(+) \%$ & $(-) \%$ & & \\
\hline \multicolumn{5}{|l|}{ Penggunaan Alas Kaki } \\
\hline $\mathrm{Ya}$ & $\begin{array}{c}0 \\
(0 \%)\end{array}$ & $\begin{array}{c}15 \\
(100 \%)\end{array}$ & $\begin{array}{c}15 \\
(100 \%)\end{array}$ & $X^{2}=0,068$ \\
\hline Tidak & $\begin{array}{c}3 \\
(20 \%)\end{array}$ & $\begin{array}{c}12 \\
(80 \%)\end{array}$ & $\begin{array}{c}15 \\
(100 \%)\end{array}$ & $\mathrm{P}>0,05$ \\
\hline Total & $\begin{array}{c}3 \\
(10 \%)\end{array}$ & $\begin{array}{c}27 \\
(90 \%)\end{array}$ & $\begin{array}{c}30 \\
(100 \%)\end{array}$ & \\
\hline
\end{tabular}

(Sumber : Data Primer. 2018)

Berdasarkan hasil penelitian pada tabel 4, dari 30 sampel kerokan kuku kaki petani kelapa sawit, didapatkan hasil, yaitu pada petani kelapa sawit yang tidak menggunakan alas kaki sebanyak 3 sampel $(20 \%)$ dan petani kelapa sawit yang menggunakan alas kaki sebanyak 0 sampel $(0 \%)$.

\section{Pembahasan}

Pemeriksaan ini dilakukan dengan menggunakan 2 metode yaitu, metode pemeriksaan langsung elemen jamur pada kerokan kuku kaki petani kelapa sawit dengan menggunakan larutan $\mathrm{KOH} 20 \%$ dan dengan metode biakan menggunakan media SDA $(+)$, untuk mengetahui apakah ditemukan jamur Dermatophyta sebagai jamur penyebab Tinea unguium yang menginfeksi kuku kaki pada 30 orang petani kelapa sawit di Desa Pauh Menang Kecamatan Pamenang Kabupaten Merangin, Jambi.

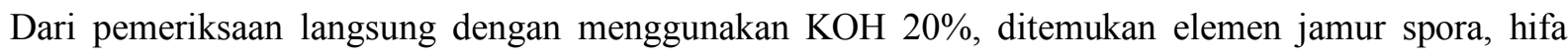
sejati dan spora, hifa sejati dan artrospora, dan tidak ditemukan elemen jamur. Pemeriksaan langsung

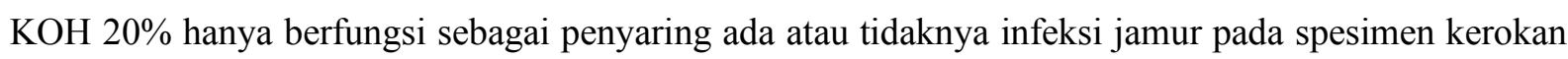
kuku kaki. Meskipun hasil pemeriksaan secara langsung $\mathrm{KOH} 20 \%$ terdapat hasil yang negatif (tidak ditemukan elemen jamur) akan tetapi dengan pemeriksaan biakan SDA (+) jamur dapat teridentifikasi. Pada pemeriksaan langsung $\mathrm{KOH} 20 \%$ terdapat hasil yang negatif (tidak ditemukan elemen jamur) bisa dikarenakan oleh beberapa faktor, yaitu seperti elemen spora yang ada dispesimen kerokan kuku tidak begitu banyak, dan elemen spora yang ada tertutup oleh kotoran dari spesimen kerokan kuku. Sedikitnya ditemukan elemen artrospora pada pemeriksaan langsung dikarenakan spesimen yang diambil terlalu sedikit hal ini disebabkan pada waktu penggambilan spesimen kerokan kuku terjadi kesulitan karena kuku mengeras dan rusak sehingga kerokan kuku yang didapat sedikit, elemen 
artrospora yang ada dispesimen kerokan kuku tidak begitu banyak sehingga tidak ditemukan elemen artrospora, dan kurangnya proses pelisisan sel epitel oleh KOH $20 \%$.

Berdasarkan pemeriksaan biakan dengan media SDA (+). Sejumlah penelitian menyebutkan bahwa penyebab utama dari Tinea unguium adalah jamur Dermatophyta khususnya Trichophyton rubrum karena diduga memiliki adaptasi virulensi yang lebih baik dan merupakan jamur antropofilik, Setianingsih, dkk, (2015). Hasil penelitian ini lebih rendah dari hasil penelitian sebelumnya tentang pemeriksaan jamur Dermatophyta kuku kaki petani di Desa Bunter Blok Cileudug Kecamatan Sukadana Kabupaten Ciamis dengan faktor resiko penggunaan alas kaki yang dilakukan oleh Widiati, dkk, (2016), dengan hasil jamur Dermatophyta dengan spesies Trichophyton mentagrophytes 23 orang (70\%) dan Trichophyton rubrum 6 orang (20\%) dari 30 sampel. Selain itu juga penelitian ini ditemukan jamur Aspergillus niger, Aspergillus flavus, Penicillium, Mycelia sterillia, dan Monillia sitophila merupakan jamur kontaminan yang hidup bebas dan terdapat dimana-mana. Jamur dapat mengkontaminasi dalam bentuk spora yang terdapat banyak diudara. Umumnya keadaan lingkungan yang kurang baik, lembab ini juga dapat mempengaruhi terdapatnya jamur Aspergillus niger, Aspergillus flavus, Penicillium, Mycelia sterillia, dan Monillia sitophila yang bisa terbawa sporanya oleh udara kemudian menempel pada kuku. Infeksi yang terjadi juga bervariasi ada sampel yang terinfeksi oleh satu jamur, ada pula yang terinfeksi oleh dua spesies jamur. Dilihat dari rendahnya hasil penelitian ini dapat disebabkan oleh beberapa hal yaitu, dikarenakan tumbuhnya jamur kontaminan yang cenderung lebih cepat yakni sekitar 3-5 hari sehingga menyebabkan jamur Dermatophyta tertutupi oleh jamur kontaminan, dapat juga disebabkan oleh karakteristik subjek penelitian baik demografi maupun perilaku, dan mulai bertambahnya kesadaran petani akan pentingnya menjaga kebersihan dan kesehatan kuku kaki.

Berdasarkan pemeriksaan terhadap variabel yang diteliti yaitu, penggunaan alas kaki saat bekerja, ternyata petani yang bekerja tidak menggunakan alas kaki menunjukan hasil beresiko terinfeksi Tinea unguium yaitu sebanyak 3 orang (20\%) dengan spesies Trichophyton rubrum, hasil penelitian ini juga didukung oleh hasil wawancara dan pengamatan sebelumnyaa dengan para petani kelapa sawit sebelum dilakukan pengambilan spesimen bahwa kuku kaki petani terdapat kelainan, seperti permukaan kuku tidak rata dan warna kuku coklat kekuningan. Hasil penelitian ini sesuai dengan peneliti sebelumnya oleh (Widiati, dkk. 2016) tentang pemeriksaan jamur Dermatophyta kuku kaki petani di Desa Bunter Blok Cileudug Kecamatan Sukadana Kabupaten Ciamis dengan faktor resiko penggunaan alas kaki, dengan kebiasaan petani saat bekerja tidak menggunakan alas kaki dengan hasil jamur Dermatophyta dengan spesies Trichophyton mentagrophytes 23 orang (70\%) dan Trichophyton rubrum 6 orang (20\%) dari 30 sampel. Hasil penelitian ini juga sesuai dengan teori menurut (Zulkoni, 2010, Andani, 2016, Aisyah, 2017), hal tersebut dikarenakan petani yang sehari-harinya bertani memiliki kebiasaan tidak menggunakan alas kaki saat melakukan pekerjaannya, sehingga lumpur dengan mudah masuk ke dalam kuku kaki dan menyebabkan perkembangan jamur. Setelah dilakukan 
uji Chi-Square pada penelitian ini, diketahui $\mathrm{P}$ value $0,068(\mathrm{p}>0,05)$ yang berarti tidak terdapat hubungan yang bermakna antara penggunaan alas kaki saat bekerja di kebun kelapa sawit dengan keberadaan jamur Dermatophyta penyebab Tinea unguium, yang artinya petani yang bekerja menggunakan alas kaki dan tidak menggunakan alas kaki sama-sama memiliki resiko untuk terinfeksi jamur Dermatophyta penyebab Tinea unguium pada kuku kaki petani kelapa sawit.

\section{SIMPULAN}

Dari hasil pemeriksaan 30 spesimen kerokan kuku kaki petani kelapa sawit di Desa Pauh Menang Kecamatan Pamenang Kabupaten Merangin, Jambi dapat disimpulkan bahwa : Pada pemeriksaan langsung ditemukan elemen jamur sebanyak $77 \%$ dan tidak ditemukan elemen jamur atau negatif sebanyak 23\%. Didapatkan elemen jamur yang mengindikasikan jamur Dermatophyta penyebab Tinea unguium yaitu, hifa sejati dan artrospora. Didapatkan hasil 3 sampel (10\%) ditemukan jamur Dermatophyta penyebab Tinea unguium yaitu spesies Trichophyton rubrum pada petani yang tidak menggunakan alas kaki saat bekerja dikebun kelapa sawit. Tidak adanya hubungan yang bermakna antara penggunaan alas kaki dengan keberadaan jamur Dermatophyta penyebab Tinea unguium pada kuku kaki petani kelapa sawit.

\section{UCAPAN TERIMA KASIH}

Penulis mengucapkan terima kasih kepada petani kelapa sawit di Desa Pauh Menang Kecamatan Pamenang Kabupaten Merangin, Jambi, Kepala Laboratorium Biologi Fakultas Kesehatan Universitas MH Thamrin Jakarta dan Prodi D III Analis Kesehatan Fakultas Kesehatan Universitas MH Thamrin. dalam penelitian ini.

\section{DAFTAR PUSTAKA}

1. Adistaya. (2013). Penelitian Onikomikosis. 1-2.

2. Aisyah, R.N, Keberadaan Jamur Penyebab Tinea Unguium pada Petani di Kampung Caringin Kurung Desa Sukasari Kecamatan Kaduhejo, Padeglang Banten dan Faktor yang Mempengaruhinya, Karya Tulis Ilmiah, Fakultas Kesehatan, Universitas MH. Thamrin, Jakarta, 2017.

3. Alberta, The Provlab Story. http://www.provlab.ab.ca/, 2007.(Diakses 25 Juni 2018).

4. Amran, P, Jurnal Media Analis Kesehatan Vol 1, No 1, Hal: 47, 2010.

5. Bramono, K, Onikomikosis ; Dermatomikosis Superfisialis, Buku Pedoman Untuk Dokter dan Mahasiswa Kedokteran, FKUI, Jakarta, Hal; 46-47. 2001.

6. Bramono, K. Pemaparan Tentang Jamur, FKUI, Jakarta, 2004.

7. Dinas Perkebunan Indonesia, Kelapa Sawit, $2007: 1$ 
8. Eliss, David, Mycology Online: National Mycology University of Adelaide. http://www.mycology.adelaide.edu.au/virtual/2009/ID2-May09.html, 2015. (Diakses 30 Juni 2018).

9. $\quad$ Faradilla,. N., Nababan, M., \& Mardhiya., W. R., Kerion celsi. Files of DrsMed. 2009.

10. Gandjar,. Indrawati., \& Sjamsuridzal. W., O. A., Mikologi Dasar dan Terapan, Yayasan Obor Indonesia, Jakarta, Hal : 10-93, 2006.

11. Goeser, A. Kulit, Rambut, Kuku. Hal: 270-271, 2009.

12. Graham, Brown, R. Burns, T., Lecture Notes on Dermatologi. $8^{\text {th }}$ ed, Erlangga, Jakarta, Hal : 6 , 2005.

13. Graham, Robin, dkk., Lecture Notes on Dermatologi. Jakarta, Erlangga, 2005.

14. Harahap, M., Kelainan Kuku, Ilmu Penyakit Kulit, Hipokrates, Jakarta, Hal : 175, 2000.

15. Husein, A.A., Study of Characteristicc Features of Pleomorphic Epidermophyton flocossum. Journal of Enviromental Research. 3(2): 132-134. 2009.

16. Irianto, K., Bakteriologi, Mikilogi \& Virologi Panduan Medis \& Klinis. Jakarta. 2014.

17. Jawetz, Melnick \& Adelberg., Mikrobiologi Kedokteran Edisi Ke 25. Jakarta: EGC. 2010.

18. Kurniati, \& Rosita, C., Etiopatogenesis Dermatofitosis. 247-248. 2008.

19. Madani, A., Infeksi Jamur Kulit. Jakarta. 2000.

20. Mekkes, Jan, R., Dermatosis Tinea Korporis Ringworm. http://www.huidziekten.nl/ . 2014. (Diakses 25 Juni 2018).

21. Mulyati., Sjarifuddin P. K., Susilo J., Parasitologi Kedokteran, $4^{\text {th }}$ ed, In: Sutanto I, Ismid I, Sjarifudin P, Sungkar S, Editor, FKUI, Jakarta, Hal: 317, 2008.

22. Mulyati, "Buku Penuntun Pratikum Mikologi". Jamur Dermatophyta, Universitas MH. Thamrin Jurusan Analis Kesehatan, Jakarta, Hal: 22-45, 2017.

23. Nurcahyono, E., Identifikasi Tenia Pedis pada Pekerja Cuci Motor atau Mobil di Wilayah Jakarta Timur, Jakarta, 2007.

24. Putra, I.B., Onikomikosis, Laporan Penelitian, Universitas Sumatra Utara Jurusan Kedokteran, Medan, 2008.

25. Rosandi, M. Teguh., Artikel Ilmiah Penyakit Tinea unguium. http://www.edwarmnur.com. 2014. (Diakses, 25 Juni 2018).

26. Setianingsih, I., Arianti, D., \& Fadilly, A. Prevalensi, Penyebab dan Analisis Faktor Resiko Infeksi Tinea unguium pada Peternakan Babi di Kalimantan Tanah Sidang, Provinsi Kalimantan Tengah, Jurnal Buski, Vol 5, No.3, Hal: 155-161, 2015.

27. Siregar, R, S., Penyakit Jamur Kulit. Jakarta, 1995.

28. Siregar, Penyakit Jamur Kulit, Penerbit buku kedokteran, Palembang, 2005: 1-7, 17-23, 33-34.

29. Soedarto., Mikrobiologi Kedokteran. Jakarta, Sagung Seto: 2005.

30. Sudarman., Tinea unguium. (11 Oktober 2016).

31. Sungkar, S, D., Buku Ajar Parasitologi Kedokteran edisi ke empat. Jakarta: FKUI. 2009.

32. Sujana, Y., Terapi Denyut Itrakonazol pada Kasus Tinea unguium. Fakultas Kedokteran Universitas Udayana, Denpasar-Bali, 4. 2012.

33. Tosti, Antonella., Daniel Ralph., Piaccini Bianca Maria., Lorizzo Matilde : Color Atlas of Nails, Springer, New York, 2010.

34. Wibowo, D.S., Anatomi Tubuh Manusia. PT Grasindo, Jakarta, 2005. Putra, I.B., Onikomikosis, Laporan Penelitian, Universitas Sumatra Utara Jurusan Kedokteran, Medan, 2008.

35. Widianti, M. dkk., Pemeriksaan Jamur Dermatophyta Kuku Kaki Petani di Desa Buntar Blok Cileudug Kecamatan Sukadana Kabupaten Ciamis. Ciamis : Karya Tulis Ilmiah. 2016.

36. Zainuddin, A, A., Oendari, A., Putri, A., \& Natsir, B., Panduan Praktik Klinis Bagi Dokter di Fasilitas Pelayanan Kesehatan Primer. Jakarta: PB IDI. 2014.

37. Zulkoni, Akhsin., Parasitologi. Yogyakarta: Muha Medika. 2010.

38. (http://Arifsubarkah.wordpress.com/2010/01/02/Fungsi-kemiskinan Ciri-ciri Manusia Yang Hidup di Bawah Garis Kemiskinan.go.id) 